\title{
Predictive values of serum phospholipase A2 receptor antibody and urinary IgG, a1- macroglobulin in patients with idiopathic membranous nephropathy and nephrotic syndrome
}

Lili Liu

Beijign Hospital https://orcid.org/0000-0003-2259-8990

Haitao Wang

Beijing Hospital

Ban Zhao

Beijing Hospital

Xin Liu

Beijing Hospital

Ying Sun

Beijing Hospital

Yonghui Mao (D maoyonghui0214@bjhmoh.cn )

Beijing Hospital https://orcid.org/0000-0003-0387-729X

\section{Research}

Keywords: idiopathic membranous nephropathy, phospholipase A2 receptor antibody, urinary IgG, urinary a1- macroglobulin, nephrotic syndrome

Posted Date: May 28th, 2020

DOI: https://doi.org/10.21203/rs.3.rs-29945/v1

License: (c) (i) This work is licensed under a Creative Commons Attribution 4.0 International License. Read Full License 
Table 4 Predictors of poor renal outcome by Cox regression analysis in patients with idiopathic membranous nephropathy and nephrotic syndrome

\begin{tabular}{llll}
\hline Variable & HR & $95 \% \mathbf{C l}$ & p value \\
\hline Univariate analysis & & & \\
$\quad$ Sex, male & 1.731 & $0.459-6.529$ & 0.418 \\
Age & 1.021 & $0.981-1.064$ & 0.307 \\
Serum PLA2R-Ab & 1.002 & $1.001-1.003$ & 0.002 \\
Creatinine & 1.010 & $0.988-1.032$ & 0.373 \\
eGFR & 0.985 & $0.960-1.011$ & 0.206 \\
Albumin & 0.827 & $0716-0.955$ & 0.010 \\
24-hour proteinuria & 1.196 & $1.012-1.415$ & 0.036 \\
Urinary lgG/Cr & 1.027 & $1.013-1.041$ & $<0.001$ \\
Urinary $\alpha 1 \mathrm{~m} / \mathrm{Cr}$ & 1.158 & $1.032-1.300$ & 0.013 \\
$\quad$ Urinary NAG/Cr & 1.060 & $1.034-1.086$ & $<0.001$ \\
Multivariate analysis & & & \\
Serum PLA2R-Ab & 1.002 & $1.001-1.003$ & 0.004 \\
\hline
\end{tabular}


Figures
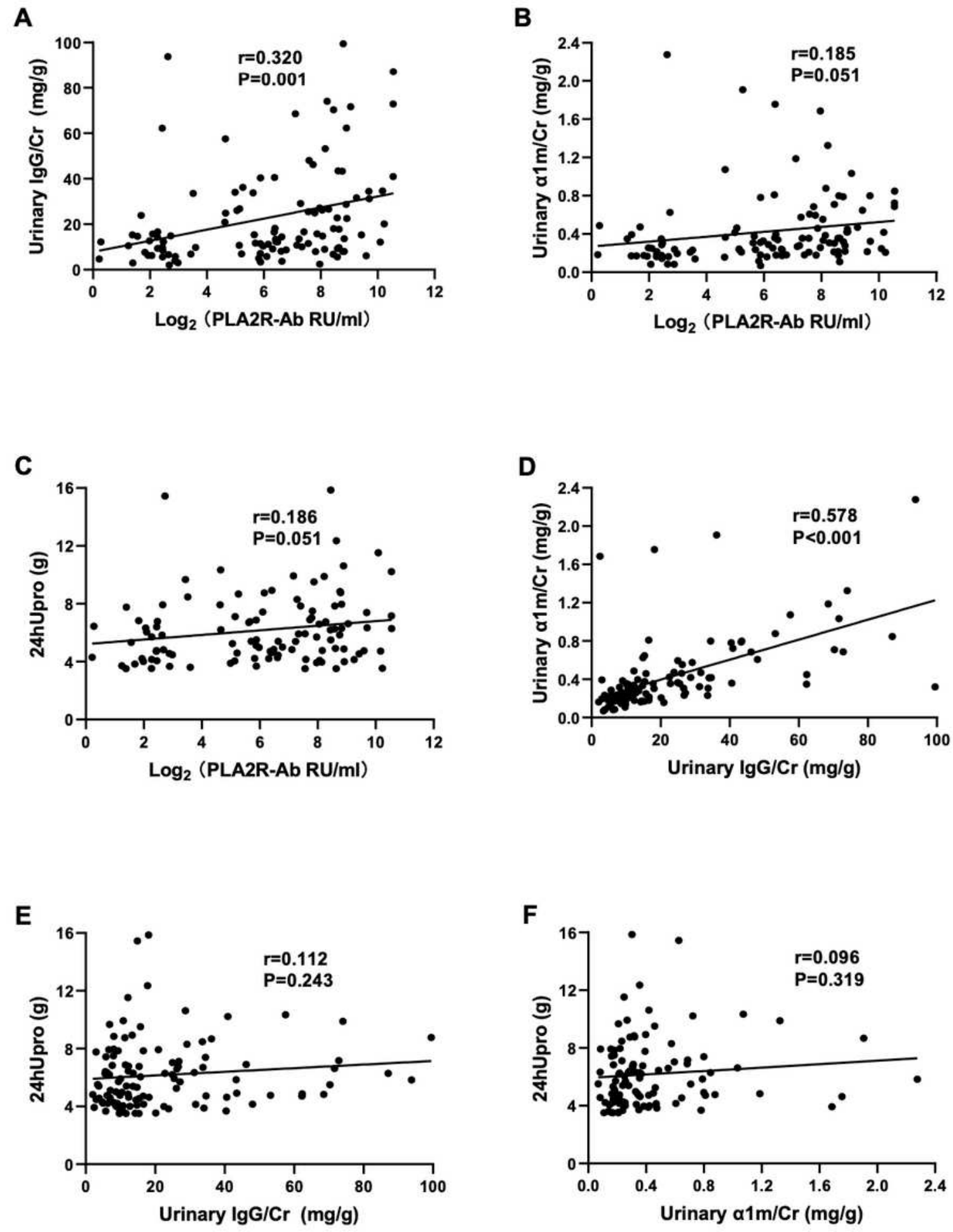

Figure 1

Correlation analysis between Log2(PLA2R-ab level) and urinary IgG/Cr (Fig A), Log2(PLA2R-ab level) and Ua1m/Cr (Fig B), UlgG/Cr and Ua1m/Cr (Fig C), 24Upro and Log2(PLA2R-ab level) (Fig D), UlgG/Cr (Fig E), Ua1m (Fig F) in the study participants. 



Figure 2

Remission rate of PLA2R-Ab (+) (Fig. A, B and C) and PLA2R-Ab (-) (Fig. D, E and F) group in 12-month observed period and at the end of follow-up. A and D: All the patients. B and E: Patients treated with immunosuppressants subgroup. $\mathrm{C}$ and F: Patients treated without immunosuppressants subgroup. 
A

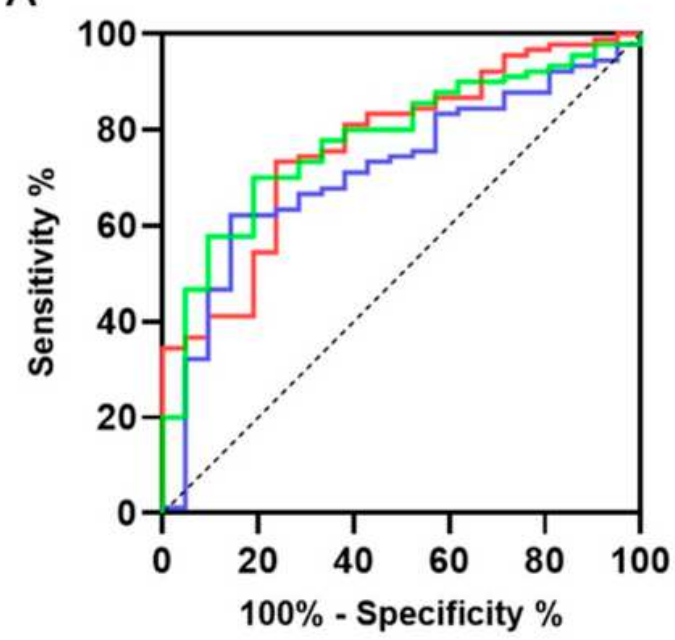

B

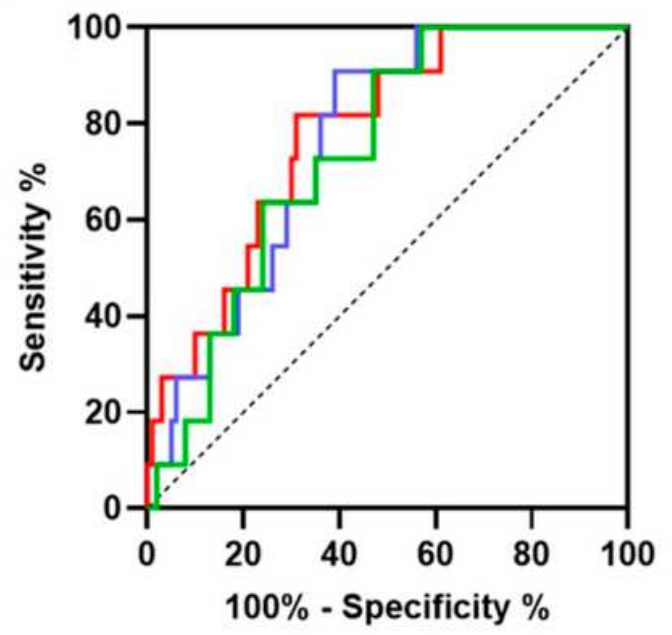

Figure 3

ROC curves for predicting non-remission and poor renal outcome. (A) Predicting non-remission: PLA2R$A b>216.93 R U / m l(A U C=0.769$, sensitivity $=76.2 \%$, specificity $=73.3 \%, p<0.001), U l g G / C r>15.29 \mathrm{mg} / \mathrm{g}$ (AUC $=0.715$, sensitivity $=85.7 \%$, specificity $=62.2 \%, p=0.002), \mathrm{U}$ a $1 \mathrm{~m} / \mathrm{Cr}>0.3547 \mathrm{mg} / \mathrm{g}$ (AUC=0.778, sensitivity $=81.0 \%$, specificity $=70.0 \%, p<0.001)$; (B) Predicting poor renal outcome: PLA2R$A b>216.93 R U / m l(A U C=0.778$, sensitivity $=81.8 \%$, specificity $=69.0 \%, p=0.003) ; U l g G / C r>15.76 \mathrm{mg} / \mathrm{g}$ $(A U C=0.758$, sensitivity $=90.9 \%$, specificity $=61.0 \%, p=0.005) ; \mathrm{Ua} 1 \mathrm{~m} / \mathrm{Cr}>0.3042 \mathrm{mg} / \mathrm{g}(\mathrm{AUC}=0.738$, sensitivity $=90.0 \%$, specificity $=53.0 \%, p=0.010$ ). 
A



C

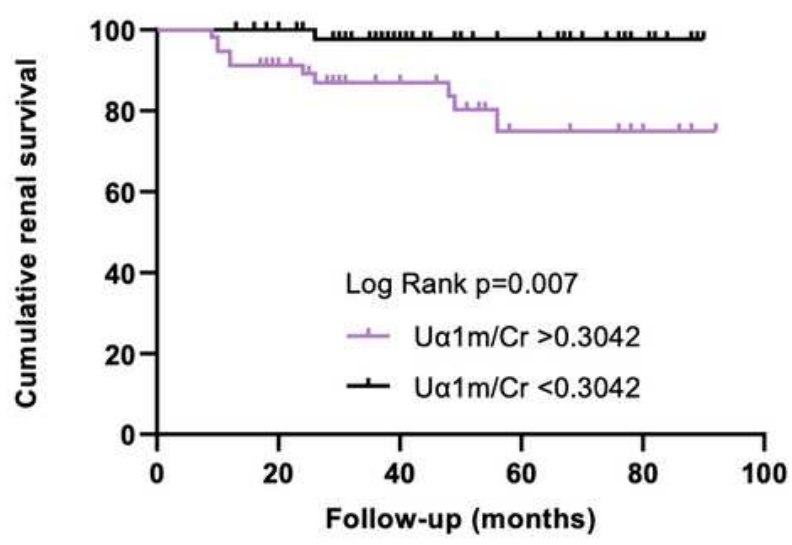

B

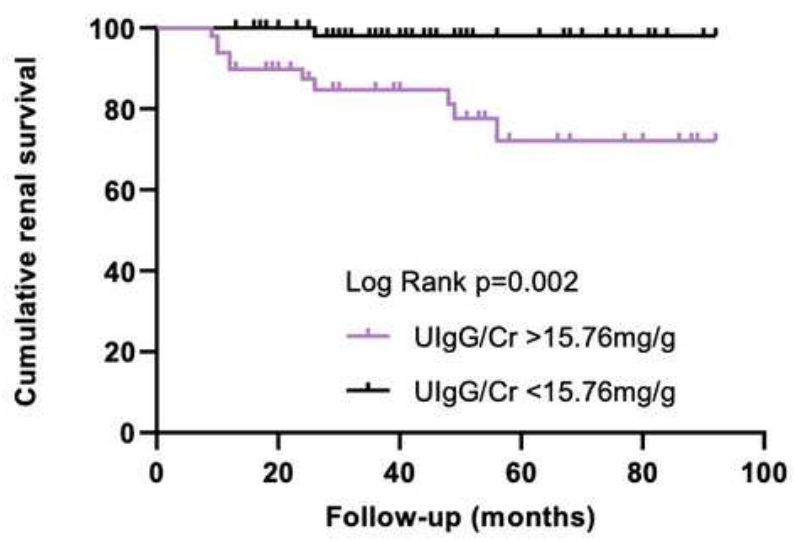

D

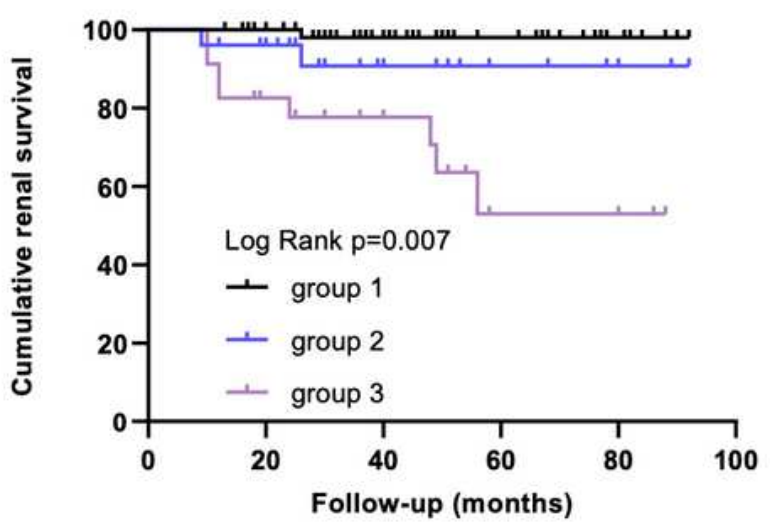

Figure 4

Kaplan-Meier survival curves of renal survival for the high and low serum anti- PLA2R-ab groups (Log rank $p=0.002$ ) (Figure $A)$, high and low UlgG/Cr groups (Log rank $p=0.002$ ) (Figure $B$ ) and high and low Ua1m groups (Log rank $p=0.007$ ) (Figure C). Kaplan-Meier survival curves of renal survival for group 1, 2, 3 (Log rank $\mathrm{p}=0.007$ ) (Figure D). Group 1 patients had no or only one high predictor at baseline; group 2 patients had any two high predictors at baseline; group 3 patients had triple high predictors. 